\title{
Interpretation of laboratory tests for prevention of the SARS-CoV-2 transmission
}

\author{
Kenichi Masui ${ }^{1}[\mathbb{D}$
}

Received: 11 September 2020 / Accepted: 23 October 2020 / Published online: 7 November 2020

(C) Japanese Society of Anesthesiologists 2020

\begin{abstract}
With the spread of severe acute respiratory syndrome coronavirus 2 (SARS-CoV-2), medical providers should take care to prevent the transmission of SARS-CoV-2 in hospitals including super-spreading. Understanding super-spreading would be useful to reduce future transmission. Some publications have shown clusters of SARS-CoV-2 such as at choir practice and in hospitals. Aerosol can be considered as a primary transmission route. As SARS-CoV-2 stability in aerosol is similar to SARS-CoV-1 with the higher reproductive number of SARS-CoV-2 than SARS-CoV-1, another factor causes rapidly spreadout, e.g. a higher discharge ratio from infected people or a higher viral intake ratio to human body. A basic research suggests higher infectivity of SARS-CoV-2 in the nose than the peripheral lung. Universal masking would be important to prevent the exposure of SARS-CoV-2 droplet to uninfected people. To detect SARS-CoV-2 infection, laboratory tests such as reverse transcription polymerase chain reaction and enzyme-linked immunosorbent assays are applied. Although sensitivity and specificity are provided for the ability of the test, positive or negative prediction values are useful to indicate the possiblity of infection or non-infection in clinical practice. We have to realize that the positive and negative prediction values depend on the sensitivity, specificity, and infection probability of the patient.
\end{abstract}

Keywords Severe acute respiratory syndrome coronavirus 2 - Coronavirus disease $2019 \cdot$ Epidemiology $\cdot$ Statistics

\section{Introduction}

After the spread of severe acute respiratory syndrome coronavirus 2 (SARS-CoV-2), anesthesia practice has dramatically changed. Medical providers should take care to protect themselves from coronavirus disease 2019 (COVID19) from infected individuals and to spread COVID-19 to someone else. Findings for the transmission of SARS-CoV-2 would help to reduce future transmission in hospitals. For infection control, laboratory tests such as reverse transcription polymerase chain reaction (RT-PCR) test or rapid antigen test may be used for screening before surgeries. Many anesthesiologists may not be familiar with the interpretation of the results of laboratory tests and the meaning of

Kenichi Masui

kenichi@masuinet.com

1 Department of Anesthesiology, Showa University School of Medicine, Hatanodai 1-5-8, Shinagawa, Tokyo 142-8666, Japan sensitivity and specificity of laboratory tests. Several examples have been presented for those understandings here.

\section{Consideration for transmission and its prevention of SARS-CoV-2}

Many publications have described the super-spreading of SARS-CoV-2 by choir practice [1], by an asymptomatic traveler possibly via polluted air in the elevator [2], at health-care facilities, and related to deep breathing in close contact such as singing at karaoke parties, cheering at clubs, having conversations in bars, and exercising in gymnasiums [3]. Based on these reports, aerosol can be considered as a primary transmission route.

One study has shown the stability of SARS-CoV-2 in aerosol and on surface compared with that of SARS-CoV-1 under the experimental condition at $21-23{ }^{\circ} \mathrm{C}, 40 \%$ relative humidity [4]. On plastic and stainless steel and in aerosol, the estimated median half-lives of SARS-CoV-2 were 6.8, 5.6, and $1.1 \mathrm{~h}$, which were similar to that of SARS-CoV-1. 
The results indicate that the difference in transmission characteristics depends on other factors. Possible causes of SARS-CoV-2 spreading rapidly are a higher discharge ratio from infected people and viral kinetics in the human body including a higher viral intake ratio to the human body. Concerning the viral kinetics, there is an important basic research showing that the infectivity of SARS-CoV-2 in the nose was higher than that in the peripheral lung [5]. The article recommends the widespread use of masks to prevent aerosol, large droplet, and/or mechanical exposure to the nasal passages. Although universal masking had doubtful preventive effect against viral infection until early in 2020, which may be due to the small virus size (approximately $120 \mathrm{~nm}$ in diameter), one experiment supports the effectiveness of surgical mask [6]. A perspective has discussed the importance and benefit of universal masking [7]. Another unpeer-reviewed archive has suggested that COVID-19 can spread from 1 to $10 \%$ of infected individuals, resulting in $80 \%$ of secondary infections with an analysis for 212 sequential SARS-CoV-2 infections [8]. The possibility of transmission from presymptomatic and asymptomatic SARS-CoV-2 infected patients, and the possibility of peak infectiousness at 2 days before to 1 day after onset from the infector-infectee paired data have been shown $[9,10]$. These publications confirmed that prevention is a principal factor to control the spread of the SARS-CoV-2 infection.

\section{Laboratory tests for SAR-CoV2 infection and their interpretation}

A good review article has been published about various laboratory tests for SARS-CoV-2 and has stated the advantages and disadvantages of the tests [11]. The most global test is an RT-PCR test, which could have a high analytical sensitivity of $95 \%$ [12]. Note that this sensitivity is NOT the sensitivity of laboratory test. In the laboratory test in an infected patient, the sample such as nasopharyngeal swab may have no SARS-CoV-2. This patient has reduced sensitivity for the laboratory test. The RT-PCR test for SARS-CoV-2 is likely to have high specificity, but moderate sensitivity [13].

Other serology-based laboratory tests are also available to detect SARS-CoV-2 infection such as enzyme-linked immunosorbent assays (ELISA) for Ig A, IgM, or IgG. The positive rate of these tests in patients with SARS-CoV-2 infection may be influenced by the duration after the onset of the infection [11, 14]. This is a disadvantage of the test. However, an article has shown that the detection ratio of IgM ELISA for SARS-CoV-2 was higher than that of RT-PCR after 5.5 days or later of the symptom onset [14]. Additionally, the combination of RT-PCR and IgM ELISA improved the detection rate [14]. Rapid antigen testing is available, but its sensitivity is moderate and is currently lower than that of
RT-PCR test [15]. As the conditions of these laboratory tests improves every day, the latest information would be found and considered in the next few years.

When a test for SARS-CoV-2 such as RT-PCR test is used before scheduled surgeries, anesthesiologists should understand the meaning of 'positive' and 'negative' results of the test. To understand the result of a laboratory test, positive predictive value (PPV) and negative predictive value (NPV) are useful. PPV indicates the ratio of truepositive patients among all test-positive patients, and NPV indicates the ratio of true-negative patients among all testnegative patients. (Table 1) However, PPV and NPV are not applicable without the infection probability of the patient or infection ratio in the population. Instead, sensitivity and specificity are applied for a laboratory test. (Table 1) These indices describe "the ability of the test", but not "the ratio of infected patients versus the result of the test."

Here, various examples show the PPV and NPV calculated using sensitivity, specificity, and probability of infection for RT-PCR test (Table 2). For the calculations, the total number of the population is set at 1000. Examples 1-1 to 1-7 show the PPV and NPV values for sensitivity of $70 \%$, specificity of 95\% [13], and infection probability between 1 and $80 \%$. When the infection probability is $1 \%$ (Ex $1-1$ in Table 2), PPV is only $12.4 \%$ and NPV is $99.7 \%$. This means that $87.6 \%$ (this is the false discovery rate: FDR) of all testpositive patients are not infected, while $0.3 \%$ (this is the false omission rate: FOR) of all test-negative patients are infected. In this case, the tested patient should be considered to have infection probability of $1 \%$ before the test. Another example is with the infection probability of $80 \%$ (Ex 1-7 in Table 2), PPV of $98.2 \%$ and NPV of $44.2 \%$. This means that $1.8 \%$ of all test-positive patients are not infected, while $55.8 \%$ of all test-negative patients are infected. The results suggest that one should not be confident only with a result of a laboratory testing and that symptoms and other findings are also important for the diagnosis of SARS-CoV-2 infection. The influence of sensitivity on PPV and NPV can be studied on

Table 1 Positive and negative predictive values for laboratory test

\begin{tabular}{|c|c|c|c|}
\hline \multicolumn{4}{|c|}{ SARS-CoV-2 infection } \\
\hline \multirow{3}{*}{ Laboratory test } & & Yes & No \\
\hline & Positive & True positive a & False positive $\mathrm{b}$ \\
\hline & Negative & False negative $\mathrm{c}$ & True negative $\mathrm{d}$ \\
\hline \multicolumn{4}{|c|}{ Positive predictive value $(\mathrm{PPV})=\frac{\text { true-positive patients }}{\text { all test-positive patients }}=\frac{\mathrm{a}}{\mathrm{a}+\mathrm{b}}$} \\
\hline \multicolumn{4}{|c|}{ Negative predictive value (NPV) $=\frac{\text { true - negative patients }}{\text { All test - negative patients }}=\frac{d}{c+d}$} \\
\hline \multicolumn{4}{|c|}{ Sensitivity $=\frac{\text { true }- \text { positive patients }}{\text { all infected patients }}=\frac{a}{a+c}$} \\
\hline \multicolumn{4}{|c|}{ Specificity $=\frac{\text { true }- \text { negative patients }}{\text { all uninfected patients }}=\frac{\mathrm{d}}{\mathrm{b}+\mathrm{d}}$} \\
\hline \multicolumn{4}{|c|}{ False discovery rate $(F D R)=\frac{\text { false }- \text { positive patients }}{\text { all test - positive patients }}=\frac{b}{a+b}$} \\
\hline \multicolumn{4}{|c|}{ False omission rate $(F O R)=\frac{\text { false }- \text { negative patients }}{\text { all test }- \text { negative patients }}=\frac{c}{c+d}$} \\
\hline
\end{tabular}


Table 2 Examples of positive and negative predictive value for RT-PCR test in patients with suspected SARS-CoV-2 infection

\begin{tabular}{|c|c|c|c|c|c|c|c|c|c|}
\hline Ex & Sens & Spec & Prob & $\mathrm{TP}$ & FP & FN & $\mathrm{TN}$ & PPV & NPV \\
\hline $1-1$ & 70 & 95 & 1 & 7 & 50 & 3 & 940 & 12.4 & 99.7 \\
\hline $1-2$ & 70 & 95 & 5 & 35 & 48 & 15 & 903 & 42.4 & 98.4 \\
\hline $1-3$ & 70 & 95 & 10 & 70 & 45 & 30 & 855 & 60.9 & 96.6 \\
\hline $1-4$ & 70 & 95 & 20 & 140 & 40 & 60 & 760 & 77.8 & 92.7 \\
\hline $1-5$ & 70 & 95 & 40 & 280 & 30 & 120 & 570 & 90.3 & 82.6 \\
\hline $1-6$ & 70 & 95 & 60 & 420 & 20 & 180 & 380 & 95.5 & 67.9 \\
\hline $1-7$ & 70 & 95 & 80 & 560 & 10 & 240 & 190 & 98.2 & 44.2 \\
\hline $2-1$ & 80 & 95 & 1 & 8 & 50 & 2 & 941 & 13.9 & 99.8 \\
\hline $2-2$ & 80 & 95 & 5 & 40 & 48 & 10 & 903 & 45.7 & 98.9 \\
\hline $2-3$ & 80 & 95 & 10 & 80 & 45 & 20 & 855 & 64.0 & 97.7 \\
\hline $2-4$ & 80 & 95 & 40 & 320 & 30 & 80 & 570 & 91.4 & 87.7 \\
\hline $2-5$ & 80 & 95 & 80 & 640 & 10 & 160 & 190 & 98.5 & 54.3 \\
\hline $3-1$ & 90 & 95 & 1 & 9 & 50 & 1 & 941 & 15.4 & 99.9 \\
\hline $3-2$ & 90 & 95 & 5 & 45 & 48 & 5 & 903 & 48.6 & 99.4 \\
\hline $3-3$ & 90 & 95 & 10 & 90 & 45 & 10 & 855 & 66.7 & 98.8 \\
\hline $3-4$ & 90 & 95 & 40 & 360 & 30 & 40 & 570 & 92.3 & 93.4 \\
\hline $3-5$ & 90 & 95 & 80 & 720 & 10 & 80 & 190 & 98.6 & 70.4 \\
\hline $4-1$ & 70 & 97 & 1 & 7 & 30 & 3 & 960 & 19.1 & 99.7 \\
\hline $4-2$ & 70 & 97 & 5 & 35 & 29 & 15 & 922 & 55.1 & 98.4 \\
\hline $4-3$ & 70 & 97 & 10 & 70 & 27 & 30 & 873 & 72.2 & 96.7 \\
\hline $4-4$ & 70 & 97 & 40 & 280 & 18 & 120 & 582 & 94.0 & 82.9 \\
\hline $4-5$ & 70 & 97 & 80 & 560 & 6 & 240 & 194 & 98.9 & 44.7 \\
\hline $5-1$ & 90 & 97 & 1 & 9 & 30 & 1 & 960 & 23.3 & 99.9 \\
\hline $5-2$ & 90 & 97 & 5 & 45 & 29 & 5 & 922 & 61.2 & 99.5 \\
\hline $5-3$ & 90 & 97 & 10 & 90 & 27 & 10 & 873 & 76.9 & 98.9 \\
\hline $5-4$ & 90 & 97 & 40 & 360 & 18 & 40 & 582 & 95.2 & 93.6 \\
\hline $5-5$ & 90 & 97 & 80 & 720 & 6 & 80 & 194 & 99.2 & 70.8 \\
\hline $6-1$ & 70 & 99 & 1 & 7 & 10 & 3 & 980 & 41.4 & 99.7 \\
\hline $6-2$ & 70 & 99 & 5 & 35 & 10 & 15 & 941 & 78.7 & 98.4 \\
\hline $6-3$ & 70 & 99 & 10 & 70 & 9 & 30 & 891 & 88.6 & 96.7 \\
\hline $6-4$ & 70 & 99 & 40 & 280 & 6 & 120 & 594 & 97.9 & 83.2 \\
\hline $6-5$ & 70 & 99 & 80 & 560 & 2 & 240 & 198 & 99.6 & 45.2 \\
\hline $7-1$ & 90 & 99 & 1 & 9 & 10 & 1 & 980 & 47.6 & 99.9 \\
\hline $7-2$ & 90 & 99 & 5 & 45 & 10 & 5 & 941 & 82.6 & 99.5 \\
\hline $7-3$ & 90 & 99 & 10 & 90 & 9 & 10 & 891 & 90.9 & 98.9 \\
\hline $7-4$ & 90 & 99 & 40 & 360 & 6 & 40 & 594 & 98.4 & 93.7 \\
\hline $7-5$ & 90 & 99 & 80 & 720 & 2 & 80 & 198 & 99.7 & 71.2 \\
\hline
\end{tabular}

$R T-P C R$ reverse transcription polymerase chain reaction, $S A R S-C o V-2$ severe acute respiratory syndrome coronavirus 2, Ex example, Sens sensitivity, Spec specificity, Prob infection probability, TP true positive, $F P$ false positive, $F N$ false negative, $T N$ true negative, $P P V$ positive predictive value, $N P V$ negative predictive value

Total number of the population (sum of TP, FP, FN, and TN people) is set at 1000 for each example comparing the Ex 1, 2, and 3. The sensitivity range 70-90\% influences NPV especially for high infection probability, but influences PPV little. The influence of specificity on PPV and NPV can be inspected when comparing Ex 1, 4, and 5 , or Ex 3, 5, and 7. The specificity range $95-99 \%$ has a large impact on PPV for lower infection probability, e.g., a change in specificity from 95 to $99 \%$ with sensitivity of $70 \%$ increases PPV from $12.4 \%$ to $41.4 \%$ on infection probability of $1 \%$ (Ex 1-1 versus Ex 6-1) or PPV from $42.4 \%$ to $88.6 \%$ on infection probability of 10\% (Ex 1-3 versus Ex 6-3). A change in specificity between these ranges has little impact on NPV.

All laboratory tests are not perfect. The "infected patient" can have a "negative" result of the test (this is "false negative") similar to an "infected patient" being "asymptomatic." But, is laboratory test useless? The answer is "NO." For the 
special population, laboratory test would be useful. When the infection probability is $\leq 5 \%$ in a patient with sensitivity $>70 \%$ and specificity $>95 \%$ of the laboratory test, NPV results in $>98 \%$. In other words, the negative result of the test means uninfected in $>98 \%$ patients. In contrast, when the infection probability is $\geq 40 \%$ in a patient, with sensitivity of $70 \%$ and specificity $>95 \%$ of the laboratory test, NPV results in $<83.3 \%$. This means that $16.7 \%$ in the "negative" population, i.e., one out of six people, is infected. For PPV, when the infection probability is $1 \%$ in a patient with sensitivity between 70 and $90 \%$ and specificity of $95 \%$ of the laboratory test, PPV results in $<16.7 \%$. This means that five "uninfected" out of six people have a "positive" result of the test ("false positive"). If you are interested in calculating PPV and NPV by yourself, you can find a good calculator in a website of an article [13]. Please realize that the PPV and NPV depend on not only sensitivity and specificity of the laboratory test, but also the infection probability of the patient.

\section{References}

1. Hamner L, Dubbel P, Capron I, Ross A, Jordan A, Lee J, Lynn J, Ball A, Narwal S, Russell S, Patrick D, Leibrand H. High SARSCoV-2 attack rate following exposure at a choir practice-Skagit County, Washington, March 2020. MMWR Morb Mortal Wkly Rep. 2020;69:606-10.

2. Liu J, Huang J, Xiang D. Large SARS-CoV-2 outbreak caused by asymptomatic traveller, China. Emerg Infect Dis J. 2020;26:2260.

3. Furuse Y, Sando E, Tsuchiya N, Miyahara R, Yasuda I, Ko Y, Saito M, Morimoto K, Imamura T, Shobugawa Y, Nagata S, Jindai K, Imamura T, Sunagawa T, Suzuki M, Nishiura H, Oshitani H. Clusters of coronavirus disease in communities, Japan, JanuaryApril 2020. Emerging Infectious Disease journal. 2020;26:2176.

4. van Doremalen N, Bushmaker T, Morris DH, Holbrook MG, Gamble A, Williamson BN, Tamin A, Harcourt JL, Thornburg NJ, Gerber SI, Lloyd-Smith JO, de Wit E, Munster VJ. Aerosol and surface stability of SARS-CoV-2 as compared with SARSCoV-1. N Engl J Med. 2020;382:1564-7.

5. Hou YJ, Okuda K, Edwards CE, Martinez DR, Asakura T, Dinnon KH III, Kato T, Lee RE, Yount BL, Mascenik TM, Chen G, Olivier KN, Ghio A, Tse LV, Leist SR, Gralinski LE, Schäfer A, Dang H, Gilmore R, Nakano S, Sun L, Fulcher ML, LivraghiButrico A, Nicely NI, Cameron M, Cameron C, Kelvin DJ, de Silva A, Margolis DM, Markmann A, Bartelt L, Zumwalt R, Martinez FJ, Salvatore SP, Borczuk A, Tata PR, Sontake V, Kimple
A, Jaspers I, O’Neal WK, Randell SH, Boucher RC, Baric RS. SARS-CoV-2 reverse genetics reveals a variable infection gradient in the respiratory tract. Cell. 2020;182(429-46):e14.

6. Chan JF-W, Yuan S, Zhang AJ, Poon VK-M, Chan CC-S, Lee AC-Y, Fan Z, Li C, Liang R, Cao J, Tang K, Luo C, Cheng VC-C, Cai J-P, Chu H, Chan K-H, To KK-W, Sridhar S, Yuen K-Y. Surgical mask partition reduces the risk of noncontact transmission in a golden Syrian hamster model for coronavirus disease 2019 (COVID-19). Clin Infect Dis 2020.

7. Klompas M, Morris CA, Sinclair J, Pearson M, Shenoy ES. Universal masking in hospitals in the COVID-19 Era. N Engl J Med. 2020;382:e63.

8. Miller D, Martin MA, Harel N, Kustin T, Tirosh O, Meir M, Sorek N, Gefen-Halevi S, Amit S, Vorontsov O, Wolf D, Peretz A, Shemer-Avni Y, Roif-Kaminsky D, Kopelman Na, Huppert A, Koelle K, Stern A. Full genome viral sequences inform patterns of SARS-CoV-2 spread into and within Israel. medRxiv 2020.

9. He X, Lau EHY, Wu P, Deng X, Wang J, Hao X, Lau YC, Wong JY, Guan Y, Tan X, Mo X, Chen Y, Liao B, Chen W, Hu F, Zhang Q, Zhong M, Wu Y, Zhao L, Zhang F, Cowling BJ, Li F, Leung GM. Temporal dynamics in viral shedding and transmissibility of COVID-19. Nat Med. 2020;26:672-5.

10. Furukawa N, Brooks J, Sobel J. Evidence Supporting Transmission of Severe Acute Respiratory Syndrome Coronavirus 2 While Presymptomatic or Asymptomatic. Emerg Infect Dis J. 2020. https ://doi.org/10.3201/eid2607.201595.

11. D'Cruz RJ, Currier AW, Sampson VB. Laboratory testing methods for novel severe acute respiratory syndrome-coronavirus-2 (SARS-CoV-2). Front Cell Dev Biol. 2020;8:468.

12. Corman VM, Landt O, Kaiser M, Molenkamp R, Meijer A, Chu DK, Bleicker T, Brünink S, Schneider J, Schmidt ML, Mulders DG, Haagmans BL, van der Veer B, van den Brink S, Wijsman L, Goderski G, Romette J-L, Ellis J, Zambon M, Peiris M, Goossens H, Reusken C, Koopmans MP, Drosten C. Detection of 2019 novel coronavirus (2019-nCoV) by real-time RT-PCR. Euro Surveill. 2020;25:2000045.

13. Watson J, Whiting PF, Brush JE. Interpreting a COVID-19 test result. BMJ. 2020;369:m1808.

14. Guo L, Ren L, Yang S, Xiao M, Chang D, Yang F, Dela Cruz CS, Wang Y, Wu C, Xiao Y, Zhang L, Han L, Dang S, Xu Y, Yang Q-W, Xu S-Y, Zhu H-D, Xu Y-C, Jin Q, Sharma L, Wang L, Wang J. Profiling early humoral response to diagnose novel coronavirus disease (COVID-19). Clin Infect Dis. 2020;71:778-85.

15. Centers for Disease Control and Prevention. Interim Guidance for Rapid Antigen Testing for SARS-CoV-2, 2020. https://www.cdc. gov/coronavirus/2019-ncov/lab/resources/antigen-tests-guidelines .html. Accessed 13, October, 2020

Publisher's Note Springer Nature remains neutral with regard to jurisdictional claims in published maps and institutional affiliations. 